\title{
Atık PVC ile Zemin İyileştirme
}

\author{
Nazile URAL $^{1 \mathrm{a}}$, Ümit KUT ${ }^{1 \mathbf{b}^{* *}}$, Nurcihan GÜLSEVINÇ ${ }^{1 \mathrm{~b}}$ \\ ${ }^{1}$ Bilecik Şeyh Edebali Üniversitesi, Mühendislik Fakültesi, İnşaat Mühendisliği Bölümü, Bilecik/TÜRKIYE \\ *umit.kut@bilecik.edu.tr
}

Received/Geliş: 04.06.2020

Accepted/Kabul: 05.08.2020

\begin{abstract}
Öz: Günümüzde, nüfusun artmasına bağlı olarak güvenli inşaatların yapılabileceği araziler azalmış ve bundan dolayı taşıma gücü düşük zeminlere de inşaat yapma ihtiyacı doğmaktadır. Buna bağlı olarak, geoteknik mühendisliğinde zeminlerin iyileştirilmesi konusu gün geçtikçe daha da önem arz etmektedir. Zemin iyileştirme, yetersiz dayanıma sahip zeminlerin mekanik, fiziksel veya kimyasal iyileştirme yöntemleri ile dış yüklere karşıdayanıklı hale getirilmesidir. Literatürde, uçucu kül, firın cürufu, geri dönüştürülmüş lastik agregalar, atık cam parçaları, atık tuğla ve mermer parçaları, kimyasal katkılar, polimer malzemeler, geotekstil malzemeler ile zeminlerin iyileştirilmesi hakkında birçok çalışma bulunmaktadır. $\mathrm{Bu}$ çalışmada, $\% 10$ oranında çimentonun eklenmesiyle elde edilen çimentolu killi zemin karışımına $\% 5, \% 10$ ve $\% 15$ oranında atık PVC fiberleri eklenerek, 0 ve 28 günlük numuneler hazırlanmıştır. Hazırlanan numuneler tek eksenli basınç deneyine tabi tutulmuş ve atık PVC fiberin çimentolu killi zeminin serbest basınç mukavemeti üzerinde etkili olduğu görülmüştür.
\end{abstract}

Anahtar Kelimeler: Zemin iyileştirme, atık pvc fiberi, serbest basınç mukavemeti

\section{Soil Improvement with Waste PVC}

\begin{abstract}
Due to the increase in the population, the lands where safe constructions can be done have decreased. Therefore, there is a need to construct to grounds with low bearing capacity. Accordingly, improving the soil in geotechnical engineering is becoming more and more important day by day. Soil improvement is making the soil with insufficient strength resistant to external loads by mechanical, physical, or chemical improvement methods. There are many studies in the literature on soil improvement related to fly ash, furnace slag, recycled rubber aggregates, waste glass pieces, waste brick and marble pieces, chemical additives, polymer materials, geotextile materials. In this study, 0th and 28th days samples were prepared by adding 5\%,10\%, and $15 \%$ waste PVC fibers to a cemented clay soil obtained by adding $10 \%$ cement. The prepared samples were subjected to the uniaxial pressure test, and it was observed that the waste PVC fiber affected the free compressive strength of the cemented clay soil.
\end{abstract}

Keywords: Soil improvement, waste pvc fiber, unconfined compression strength

\section{Giriş}

İnşaat mühendisliğinde, yapıların sağlam olması gerektiği kadar yapının inşa edileceği zeminin detaşıma gücünün yüksek olması gerekmektedir. Ancak, günümüzde nüfusun artmasına bağlı olarakyapıyı güvenli bir şekilde taşıyacak, taşıma gücü yüksek araziler azalmaktadır. Bundan dolayı, çoğuzaman yapının yapılacağı zeminin mühendislik özelliklerinin iyileştirilmesi gerekmektedir. Zemin iyileştirmede temel amaç genel olarak, dayanımı düşük zeminin taşıma kapasitesini artırmak, zeminin kayma direncini artırmak, toplam oturmayı azaltıp konsolidasyonu 
hızlandırmak, zeminin potansiyel sıvılaşma riskini azaltmak, dolgu ve şevlerin stabilitesini sağlamak, istinat duvarlarını desteklemektir. Günümüzde, zeminlerin iyileştirilmesi konusu, geoteknik mühendisliğinin en temel ilgi alanlarından birisi haline gelmiştir. Taş kolon, jet grout, enjeksiyon gibi yöntemler ile, uçucu kül, fırın cürufu, geri dönüştürülmüş lastik agregalar, atık mermer, atık tuğla, kimyasal katkılar, polimer malzemeler, geotekstil malzemeler gibi katk1 malzemeleri ile zeminlerin iyileştirilmesi hakkında birçok çalışma bulunmaktadır [1-9].

Xiao ve ark. [10], geosentetik ile güçlendirilmiş duvarın arkasına lastikten üretilmiş agrega ve kötü derecelenmiş kum olmak üzere iki farklı geri dolgu malzemesi kullanarak depreme karşı duvarın davranışını incelemişlerdir. Araştırmacılar bu çalışma kapsamında, laboratuvar ortamında ölçekli sarsma tablasında arazi kayıtlarından alınmış gerçek bir deprem ivmesi ile deney yapmışlardır. Araştırmacılar yaptıkları deneyler sonucunda, geri dolgu malzemesi olarak lastikten üretilmiş agregaların kullanılması durumunda duvarda daha az yanal deplasman, daha az düşey oturma, daha az ivmelenme, daha az statik ve dinamik gerilmelerin oluştuğunu ortaya koymuşlardır. Sonuç olarak, lastik agregaların hem hafif olması hem de dinamik yükleri bir dereceye kadar sönümlemesi bakımından, istinat duvarı gibi yapılarda geri dolgu malzemesi olarak kullanılabileceği görülmüştür.

Naeini ve Mirzakhanlari [11], geotekstillerin farklı granülometre eğrisine sahip granüler zeminlerde donatı olarak kullanılmasının zeminlerin taşıma gücü üzerindeki etkisini araştırmışlardır. Araştırmacılar yaptıkları çalışma kapsamında, laboratuvar ortamında geotekstil ile donatılandırılmış farklı granülometre eğrisine sahip zeminlerin yük-penetrasyon davranışını incelemek için Kaliforniya Taşıma Oranı (CBR) deneylerini yapmışlardır. İlk olarak, farklı granüler zemin numuneleri üzerinde geotekstil kullanmaksızın CBR deneylerini gerçekleştirmişlerdir. Daha sonra, farklı derinliklere bir ve iki tabaka şeklinde geotekstil yerleştirerek numuneler hazırlamışlardır ve bu deney numunelerini CBR testine tabi tutmuşlardır. Araştırmacılar deney sonuçlarını karşılaştırdıklarında, granüler zeminlerde geotekstil kullanımının zeminin taşıma gücünü arttırdığını söylemişlerdir. Sonuç olarak, geotekstillerin zeminlerin mühendislik özelliklerinin iyileştirilmesinde kullanılabileceği görülmüştür.

Umu ve ark. [12], atık lastik tozunun ISO standart kumunun dinamik davranışına etkisini incelemek için bir kısım burulmalı rezonans kolon deneyini gerçekleştirmişlerdir. Araştırmacılar bu kapsamda ilk olarak, ISO standart kumunun dinamik deneylerini yaparak modül azalım (G/Gmax), sönüm oranı ve maksimum kayma modülü (Gmax) grafiklerini elde etmişlerdir. Araştırmacılar daha sonra, ISO standart kumuna ağırlıkça $\% 5, \% 10, \% 15$ oranlarında atık lastik tozu ekleyerek aynı şekilde modül azalım, sönüm oranı ve maksimum kayma modülü eğrilerini elde etmişlerdir ve her iki durumdaki grafikleri karşılaştırmışlardır. Araştırmacılar çalışma sonunda, atık lastik tozunun \%5-10 aralığında kullanılması durumunda kumun kayma dayanımını ve sönüm oranını arttırdığını, atık lastiğin geoteknik mühendisliğinde önemli bir malzeme olduğunu ve karışım oranı \%5-10 olması halinde maksimum kayma modülünde en iyi sonuçların elde edildiğini ifade etmişlerdir. Sonuç olarak, lastiğin yüksek sönümleme kapasitesi, kumun dinamik davranışı üzerinde etkili olduğu görülmektedir.

Keskin ve Laman [13], atık lastiğin kumun kayma direnci üzerindeki etkisini araştırmışlardır. Araştırmacılar, bu kapsamda kum numunelere hacimce farklı yüzdelerde lastik parçacıklarını ekleyerek lastik/kum karışımları üzerinde farklı normal gerilmeler altında kesme kutusu deneyini gerçekleştirmişlerdir ve deney sonuçları Şekil 1'de gösterilmiştir. 


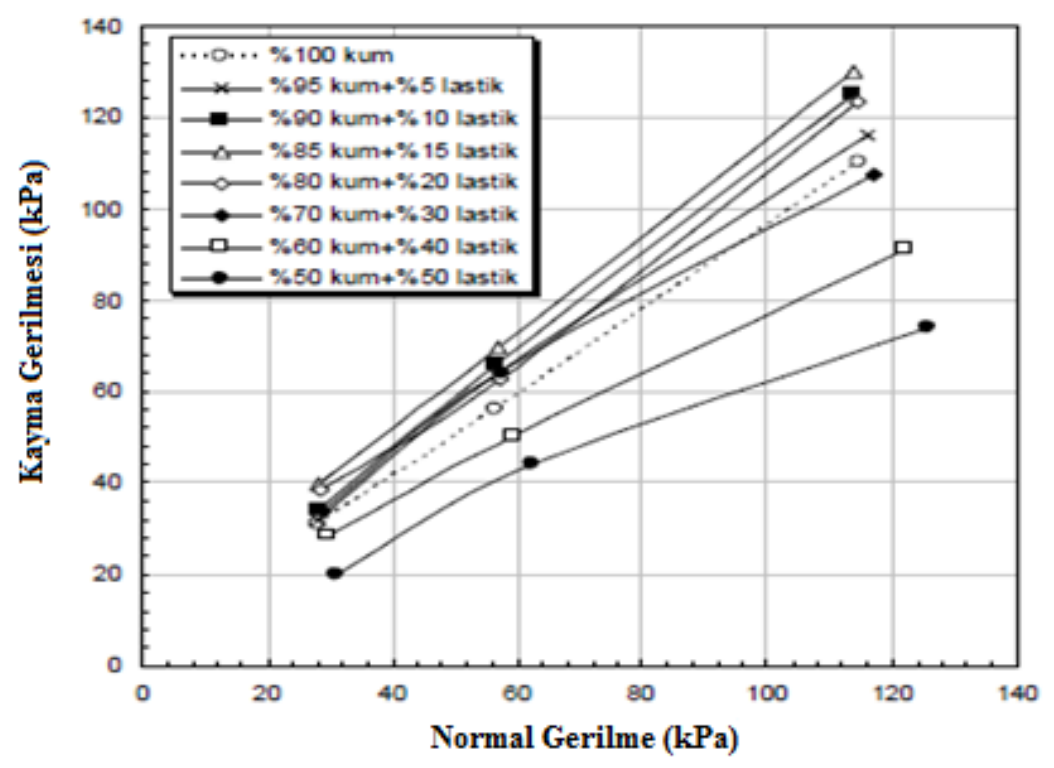

Şekil 1. Kırılma zarfları [13]

Araştırmacılar, optimum lastik oranını \%10-15 aralığında bulmuşlardır ve bu aralıktaki lastik oranının \%100 kuma göre kayma mukavemetini \%10 oranında arttırdığını söylemişlerdir. Sonuç olarak, atık lastiklerin kumlarda kullanılması halinde kayma direncinde artı̧lar olmaktadır.

Freitag [14], ince daneli zeminlerde hacimsel olarak \%1 ve $20 \mathrm{~mm}$ uzunluğunda polyester lifi katarak numuneler hazırlamıştır. Hazırlamış olduğu numunelerde kompaksiyon deneyi ile numunelerin su muhtevalılarını tespit ederek serbest basma deneyi gerçekleştirmiştir. Polyester lifi katılmış numunelerin lif içermeyen numunelere kıyasla yenilmeye karşı \% 25 'e kadar daha mukavemetli olduğu sonucuna varmıştır. Araştırmacı, çalşşmasında kullanmış olduğu naylon ve polipropilen liflerinin benzer sonuçlar verdiğini ifade ederek, liflerin $0.20 \mathrm{~mm}$ 'den ince daneli zeminlerde homojen karışmasının oldukça zor olduğunu belirtmiştir.

Kumar ve ark. [15], polyester lif ve kirecin uçucu kül-zemin karışımlarının geoteknik özellikleri üzerine etkisini incelemek üzere deneysel bir program yürütmüşlerdir. Deney kapsamında farkl1 oranlarda uçucu külü şişen zemine katmışlardır. Farklı oranlarda, rastgele yerleştirilen polyesterli, uçucu kül-zemin, kireç-zemin ve kireç uçucu kül-zemin karışımlarının geoteknik özellikleri araştırılmıştır. Deneylerde kireç ve uçucu kül sırasıyla \% 1-10 ve \% 1-20 aralığında şişen bir zemine ilave edilmiştir. Hazırlanan numuneler, kompaksiyon deneyi ve serbest basma deneyine tabi tutulmuştur. Ayrıca numuneler 7, 14 ve 28 gün küre tabi tutularak, serbest basma deneyleri yapılmıştır. Araştırmacılar, kireç ve uçucu kül için elde edilen optimum değerlere dayanarak, 28 gün küre tabi tutulacak numunelere, $\% 0, \% 0.5, \% 1.0, \% 1.5$ ve $\% 2$ düz ve kıvrımlı polyester lifleri katarak bu numunelerde de serbest basma deneyi gerçekleştirmişlerdir. Elde ettikleri sonuçların olumlu olduğunu ifade ederek şişen zeminlerde polyester, kireç ve uçucu külün kombine hareketi ile başarılı bir şekilde stabilize edilebileceği sonucuna varmışlardır.

Yetimoğlu ve Salbaş [16], fiber içeren kumların dayanımlarını direkt kesme deneyleri yaparak incelemişlerdir. Deney sonuçlarından max. dayanımın ve kumun başlangıç rijitliğinin fiber donatı oranından etkilenmediğini söylemişlerdir. Rezidüel kayma dayanımında ise sünekliğin artmasına bağlı bir artış gözlemlemişlerdir. Lee ve Manjunath [17], büyük boyutlu direk kesme deneyi ile zemin-geotekstil arayüzeyini çalışmışlardır. Bir kesme çevriminden sonra dayanımdan önemli bir azalma gözlenmiştir. Zhang ve ark. [18], 3 boyutlu donatılarla güçlendirilmiş zemini üç eksenli deney ile incelemişlerdir. 3D donatıları (galvanizli sac ve sert plastikten yapılmış) ile güçlendirilmiş 
kum üzerinde kapsamlı bir üç eksenli deneyleri gerçekleştirilmiştir. Sonuçta, çift taraflı 3D donatı elemanlarıyla kohezyon ve içsel sürtünme açısı önemli ölçüde artmıştır.

Naeini ve ark. [19], sulu polimer ile iyileştirilmiş killi zeminlerin serbest basınç dayanımını araştırmışlardır. Araştırmacı bu kapsamda, yumuşak kil, yumuşak kil $+\% 10$ bentonit ve yumuşak kil+\%20 bentonit olmak üzere üç farklı zemine $\% 2, \% 3, \% 4$ ve $\% 5$ oranlarında sulu polimer ekleyip $50 \mathrm{~mm}$ çapında ve $100 \mathrm{~mm}$ yüksekliğinde silindir numuneler hazırlamıştır. Laboratuvar ortamında hazırlanan bu numunelere 2, 4, 6, 8 ve 14 günlük kür uygulanmış ve serbest basınç deneyi uygulanmıştır. Deney sonuçlarına göre, her üç zemin türünde de optimum kür süresinin ve optimum polimer oranının sırasıyla 8 gün ve $\% 4$ olması durumunda en iyi sonuçların elde edildiği görülmüştür. Ayrıca, zeminin plastisitesi arttıkça serbest basınç mukavemetinde azalma meydana gelmektedir. Araştırmacı, belli oranlarda sulu polimer malzemesiyle iyileştirilmiş killi zeminlere, ortalama 8 günlük kür uygulandıktan sonra serbest basınç mukavemetinde yaklaşık olarak \%20 oranında artış olduğunu ortaya koymuştur. $\mathrm{Bu}$ çalışmanın sonuçlarından yola çıkarak, sulu polimerlerin killi zeminlerin mühendislik özelliklerinin iyileştirilmesinde kullanılabileceği vurgulanmıştır.

Ateş [20], polimer-çimento karışımının sıvılaşabilen zeminlerin serbest basınç dayanımına etkisini araştırmıştır. Araştırmacı bu çalışma kapsamında, kum zemine $\% 1, \% 2, \% 3$ ve $\% 4$ oranlarında polimer ve $\% 10, \% 20, \% 30$ ve $\% 40$ oranlarında çimento ekleyip optimum su muhtevalarında 150 mm çapında ve $300 \mathrm{~mm}$ yüksekliğinde silindir numuneler hazırlamıştır. Laboratuvar ortamında hazırlanan bu numunelere 7 ve 14 günlük kür uygulandıktan sonra, numuneler serbest basınç deneyine tabi tutulmuştur. Araştırmac1, en iyi sonuçları kum+\%3 polimer+\%30 çimento karışımında elde etmiştir. Deney sonuçlarına göre, kum+\%3 polimer+\%30 çimento karışımının serbest basınç mukavemeti kuma göre \%100 den daha fazla olduğu görülmektedir. Araştırmacı, polimer-çimento karışımının sıvılaşma potansiyeline sahip kumların serbest basınç mukavemetini önemli derecede arttırdığını ortaya koymuştur. Sonuç olarak, polimer malzemesinin zeminlerin iyileştirilmesinde kullanılmasının çok olumlu sonuçlar verdiği görülmüştür.

Naeini ve Sadjadi [21], atık polimer malzemelerin doygun olmayan killerin kayma direnci üzerindeki etkisini incelemişlerdir. Araştırmacılar bu kapsamda farklı plastisiteye sahip üç farklı killi zemine $\% 0, \% 1, \% 2, \% 3$ ve $\% 4$ oranlarında atık polimer ekleyip, numune hazırlamışlardır ve bu numuneleri kesme kutusu deneyine tabi tutmuşlardır. Deney sonuçlarına göre, $\% 2$ oranında atık polimer katkılı numunelerin kohezyon ve içsel sürtünme açısı değerlerinin katkısız numunelere göre önemli derecede artış gösterdiğini bulmuşlardır. Araştırmacılar, her üç zemin türünde de maksimum kayma gerilmesini \%2 oranında atık polimerin eklenmesiyle elde etmişlerdir. Ayrıca, maksimum kayma gerilmesi artışını plastisitesi düşük olan zeminde bulmuşlardır ve bu artış yaklaşık olarak $\% 25$ 'tir. Sonuç olarak, atık polimer malzemesinin killi zeminlerin mukavemet özelliklerinin iyileştirilmesinde kullanılabileceği görülmektedir.

$\mathrm{Bu}$ çalışma kapsamında, sınıflandırma deneyleri yapılarak deneylerde kullanılan zeminin sınıfı belirlenmiştir ve daha sonra sınıfı belirlenen bu zemine \%10 oranında çimentonun eklenmesiyle elde edilen çimentolu killi zemin karışımına $\% 5$, \%10 ve \%15 oranında atık PVC fiberleri eklenerek, 0 ve 28 günlük numuneler hazırlanmıștır. Laboratuvar ortamında hazırlanan bu numuneler tek eksenli basınç deneyine tabi tutularak, atık PVC fiberinin çimentolu killi zeminin serbest basınç mukavemeti üzerindeki etkisi araştırılmıştır.

\section{Malzeme}

$\mathrm{Bu}$ çalışmada kullanılan kil, yüksek plastisiteli kil $(\mathrm{CH})$ olarak belirlenmiştir (Şekil 2). Kil özellikleri Tablo 1' de verilmiştir. Kilin mineralojik bileşimi Şekil 3 a' da gösterilmiştir ve kilin minerolojik bileşimleri montmorillonit, anorthit, feldispat ve kuvarsdır. Ayrıca kullanılan kilin 
taramalı elektron mikroskobu (SEM) görüntüsü Şekil 4'te verilmiştir. Katk1 malzemesi olarak, Türkiye'deki ticari firmalardan elde edilen CEMI çimentosu kullanılmıştır. Çimentonun mineralojik bileşimi Şekil 3 b' de gösterilmektedir ve çimentonun mineralojik bileşimi yüksek oranda kalsiyum oksittir.

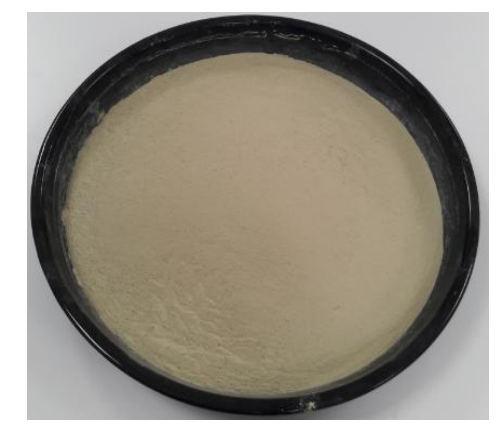

Şekil 2. Yüksek Plastisiteli Kilin $(\mathrm{CH})$ görüntüsü

Bu çalışmada, zemin malzemesi olarak Şekil 2'de gösterilen bentonit kili kullanılmıştır. Kilin zemin sınıfinı belirlemek için TS-1900/1 [22] standartına göre Şekil 3'te gösterilen hidrometre deneyi, kıvam limitleri deneyi ve piknometre deneyi yapılmıştır ve sonuçlar Tablo 1'de gösterilmiştir. Sınıflandırma deney sonuçlarından yola çıkarak, TS-1500/2000 [23]' e göre bentonit kilinin zemin sinıfı CH (Yağlı Kil) olarak bulunmuştur.

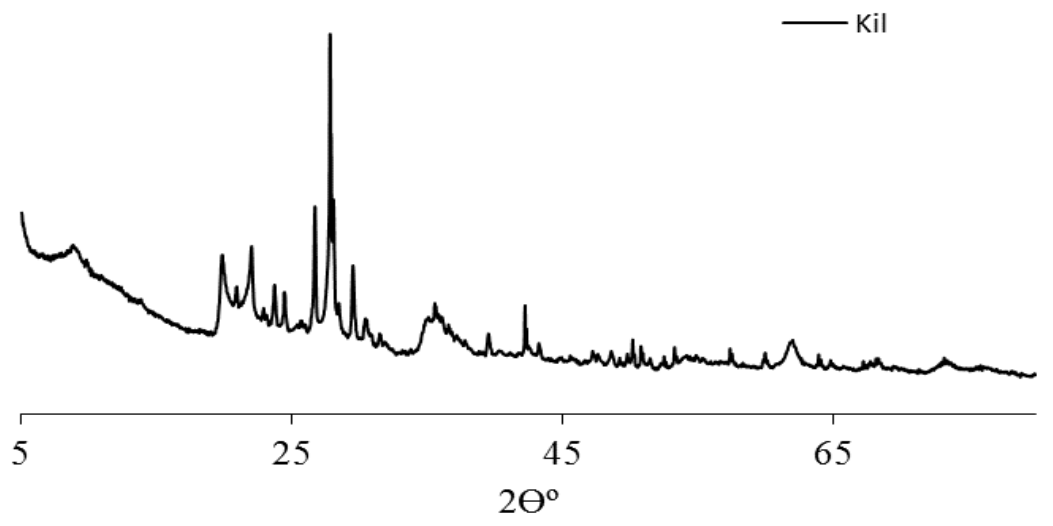

(a)

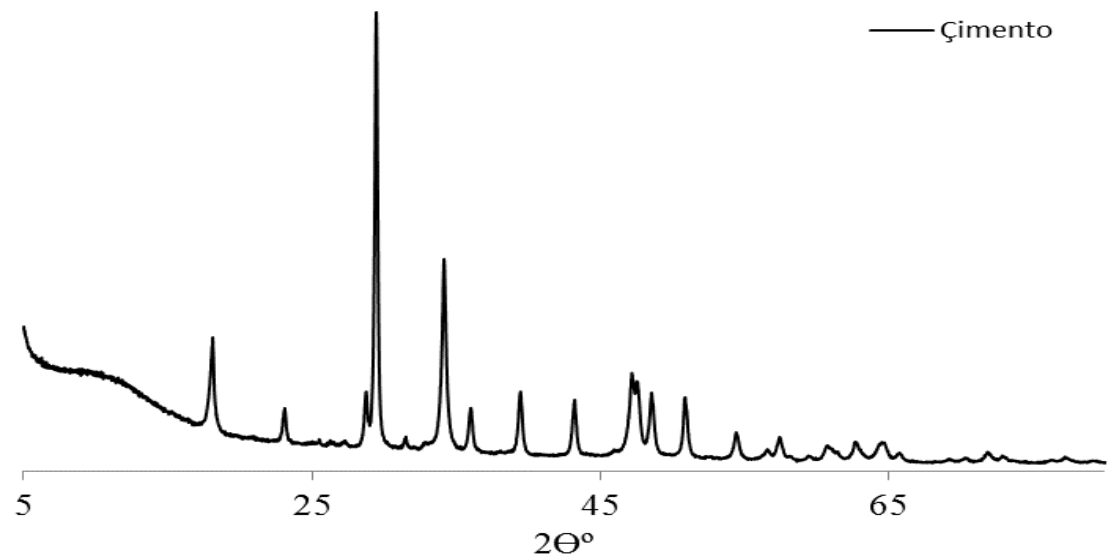

(b)

Şekil 3. a) Kilin XRD analiz sonucu b) Çimentonun XRD analiz sonucu 
Tablo 1. Sinıflandırma deney sonuçları

$\begin{array}{cc}\text { Likit Limit }^{*}(\%) & 83 \\ \text { Plastik Limit (\%) } & 33 \\ \text { Kum (\%) } & 13 \\ \text { Silt (\%) } & 46 \\ \text { Kil (\%) } & 41 \\ \text { Dane özgül ağırlığı } & 2.67 \\ \text { (g/cm }{ }^{3} \text { ) } & \\ \text { limit değeri, casagrande likit limit cihazı ile belirlenmiştir. }\end{array}$

*Likit limit değeri, casagrande likit limit cihazı ile belirlenmiştir.

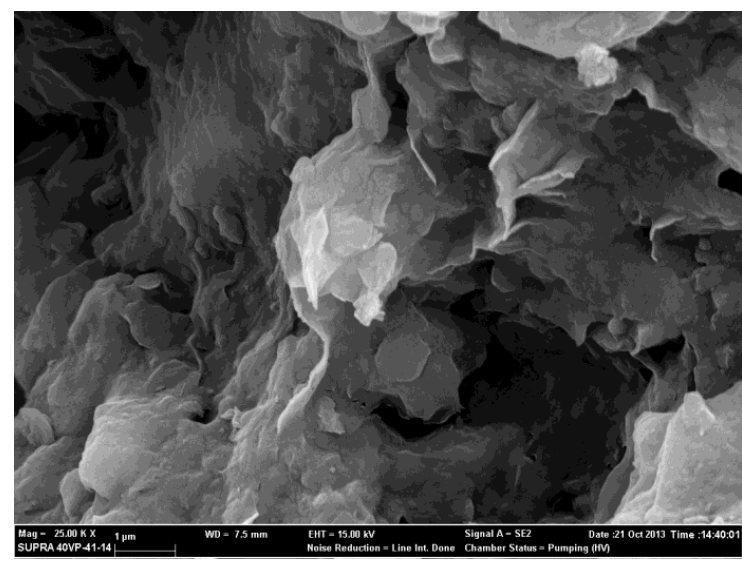

Şekil 4. CH kilinin SEM görüntüsü (x25.000)

Zemin iyileştirmesinde değerlendirmek üzere, genellikle kısaltılmış olarak PVC olarak adlandırılanyapı malzemesinin atıkları kullanılmıştır. PVC'nin açılımı polivinil klorürdür. PVC, monomeri etilen ve karbondan elde edilen bir malzemedir [22]. PVC özellikle inşaat sektöründe oldukça geniş kullanım alanı olan bir plastiktir.

Günümüzde birçok alanda PVC, geleneksel yapı malzemeler olan ahşap, beton ve çelik (kap1 ve pencere profili, boru ve tesisat malzemesi olarak) yerini almıştır. Rendelenmiş PVC atı̆g 1 Şekil 5'te gösterilmiştir.

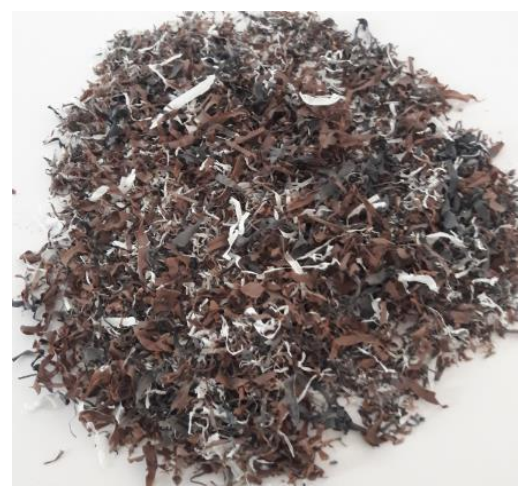

Şekil 5. Atık PVC fiberi

$\mathrm{Bu}$ çalışma kapsamında, laboratuvar ortamında sınıflandırma deneyleri yapılarak zemin sınıfı belirlenen kile \%10 oranında çimento eklenerek çimentolu killi bir zemin elde edilmiştir. Daha sonra elde edilen bu çimentolu killi zemine $\% 5, \% 10$ ve $\% 15$ oranlarında, Şekil 5 'te gösterilen atık PVC fiberi eklenerek 0 ve 28 günlük serbest basınç deneyleri yapılmak üzere silindirik numuneler hazırlanmıştır. Bu kapsamda, atık PVC fiberinin çimentolu killi zeminin serbest basınç mukavemeti üzerindeki etkisi incelenmiştir. 
Bu çalışmada kullanılan kilin zemin sınıfını belirlemek için TS-1900/1 [23] standartına göre Şekil 6'da gösterilen hidrometre deneyi, kıvam limitleri deneyi ve piknometre deneyi yapılmıştır ve sonuçlar Tablo 1'de gösterilmiştir. Sınıflandırma deney sonuçlarından yola çıkarak, TS-1500/2000 [24]' e göre deneylerde kullanılan kilin zemin sınıfı CH (Yağlı Kil) olarak bulunmuştur.
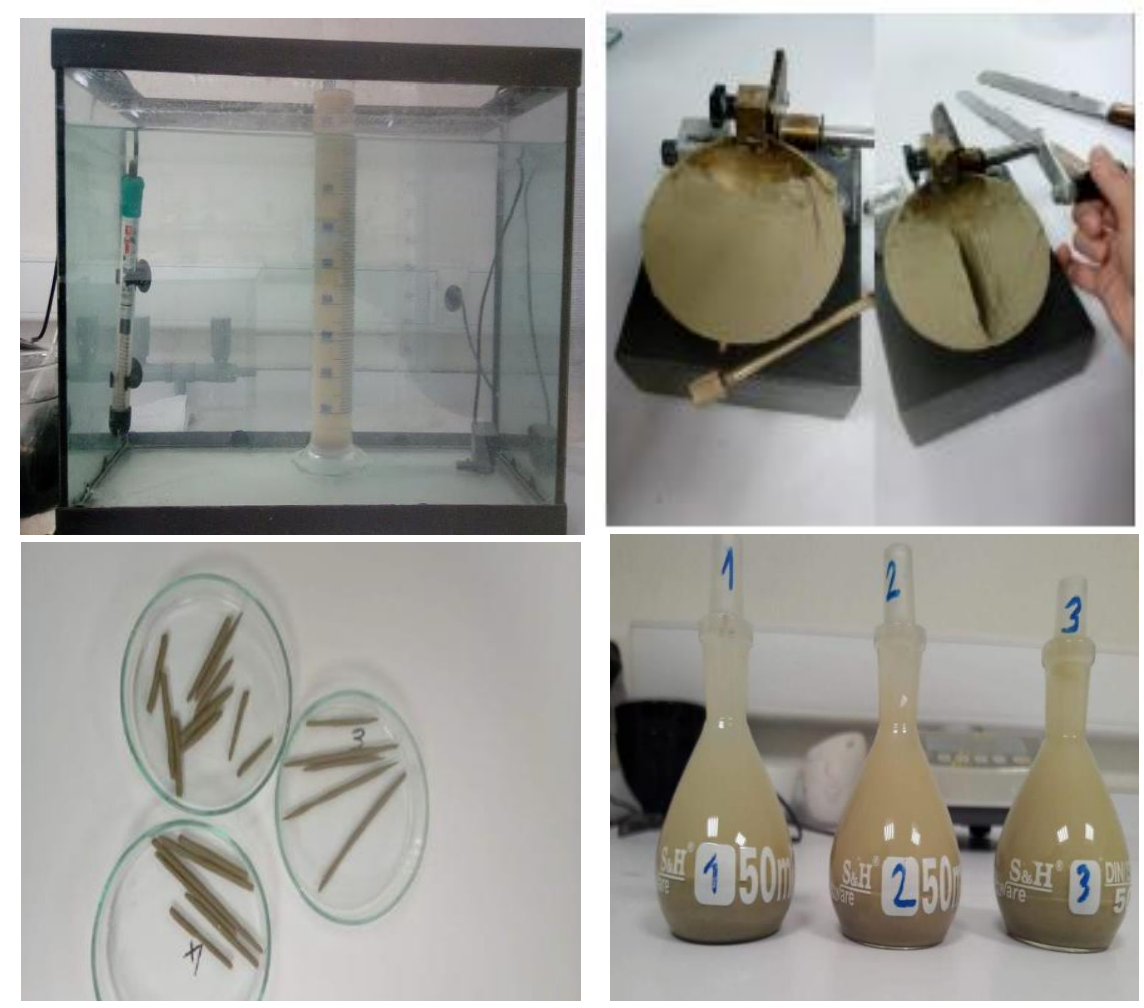

Şekil 6. Sınıflandırma deneyleri

\section{Bulgular ve Tartışma \\ 3.1. Kompaksiyon Deneyi}

Kompaksiyon deneyi, zeminin maksimum sıkışabileceği optimum su muhtevasını bulmak için yapılan mekanik bir deneydir. Bu kapsamda, TS-1900/2 [25]' e göre kil (K), kil + çimento (KÇ), kil + çimento + \%5 PVC (KÇ5PVC), kil + çimento + \%10 PVC (KÇ10PVC), kil + çimento + \%15 PVC (KÇ15PVC) olmak üzere 5 adet kompaksiyon deneyi yapılmıştır. Kilin kompaksiyon eğrisi Şekil 7'de ve karışımların sonuçları ise Tablo 2'de gösterilmişstir.

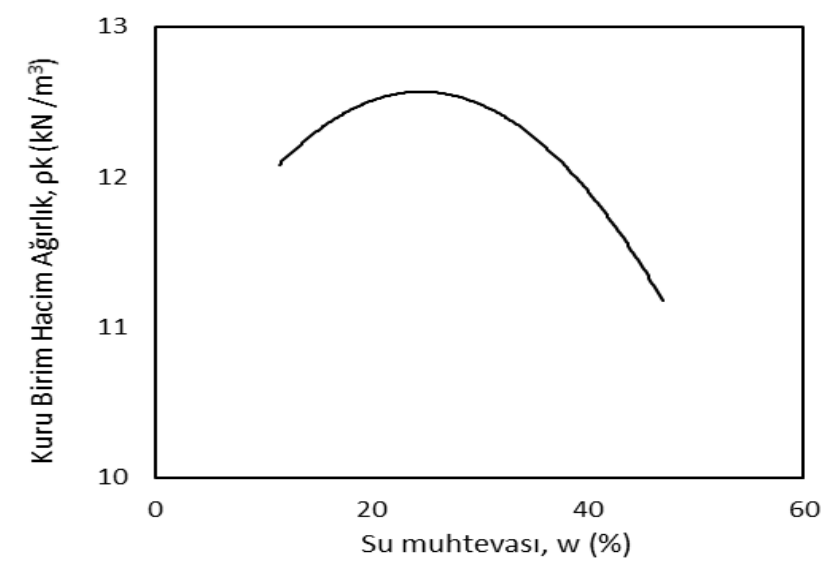

Şekil 7. CH kiline ait kompaksiyon eğrisi 
Tablo 2'de kompaksiyon deney sonuçlarına göre, çimentolu kile atık PVC fiberi eklendikçe maksimum kuru birim hacim ağırlık değerinde azalma meydana gelmiştir. Bu azalma, atık PVC fiberinin eklenmesiyle birlikte silindirik numunelerin birim hacimdeki ağırlığının azalmasından kaynaklanmaktadır. Optimum su muhtevası ise kile çimento eklenmesiyle azalırken, kil+çimento karışımına atık PVC fiberi eklenmesiyle artmıştır.

Tablo 2: Kompaksiyon deney sonuçları

\begin{tabular}{lll}
\hline & $\underline{\mathrm{w}}_{\text {opt }}(\%)$ & $\underline{\mathrm{kmax}\left(\mathrm{kN} / \mathrm{m}^{3}\right)}$ \\
\hline $\mathrm{K}$ & 25 & 12.81 \\
$\mathrm{KÇ}$ & 20 & 13.00 \\
$\mathrm{KÇ} 5 \mathrm{P}$ & 24 & 12.72 \\
$\mathrm{KÇ10P}$ & 28 & 12.27 \\
$\mathrm{KÇ15P}$ & 31 & 10.91 \\
\hline
\end{tabular}

\subsection{Serbest Basınç Deneyi}

Kompaksiyon deneyi yapılarak optimum su muhtevaları belirlenen kil (K), kil+çimento (KÇ), kil+çimento+\%5 PVC (KÇ5P), kil+çimento+\%10 PVC (KÇ10P) ve kil+çimento+\%15 PVC (KÇ15P) için TS-1900/2 (2006)'e göre silindir numuneler hazırlanmıştır. Laboratuvar ortamında hazırlanan bu silindir numulerin 0 ve 28 günlük serbest basınç mukavemet değerlerine bakılmıştır. Deney sonundaki numunlerin deformasyon şekilleri Şekil 8'de, deney sonuçları ise Şekil 9 ve Şekil 10'da gösterilmiştir.

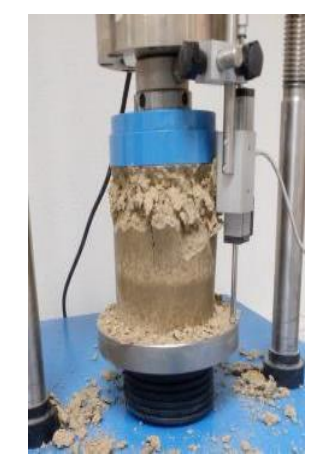

(a)
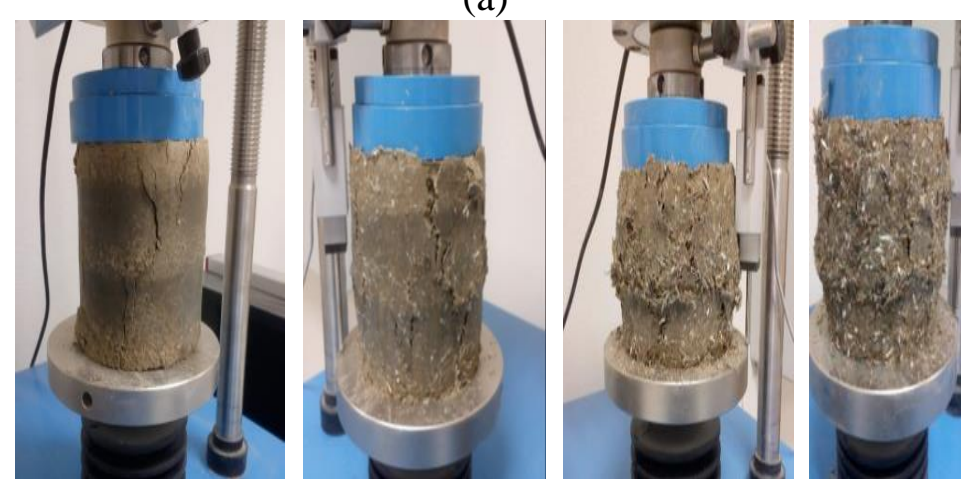

(b) 

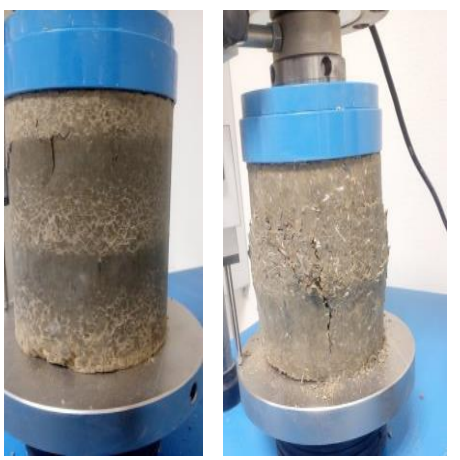

(c)
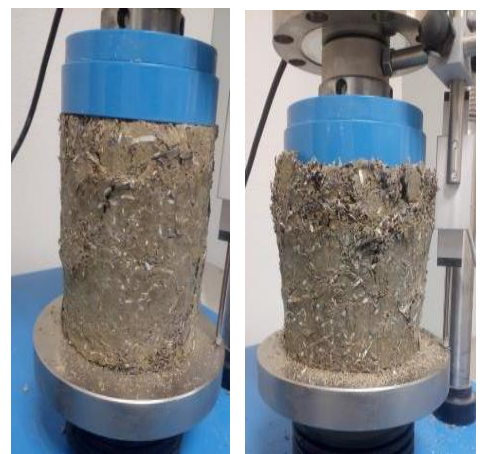

Şekil 8. a) \%100 Kil b) 0 günlük numuneler c) 28 günlük numuneler

Serbest basınç deneyi yapılan 0 günlük numunelerin deney sonuçlarına serbest basınç mukavemeti açısından bakıldığında (Şekil 9); çimentolu killi zemine \%10 oranında atık PVC fiberinin katkısıyla en iyi sonuç elde edilmiştir. \%10 atık PVC fiberinin çimentolu killi zeminin serbest basınç dayanımını yaklaşık olarak \%70 oranında arttırdığı görülmektedir. 0 günlük numunelerin deney sonuçlarına deformasyon açısından bakıldığında, atık PVC fiber oranının artmasına bağlı olarak \%30'lara varan deformasyonlara kadar numunenin yük altında dayanım gösterdiği görülmektedir. Bu durum, atık PVC fiberinin zemine süneklik kazandırdığını göstermektedir.

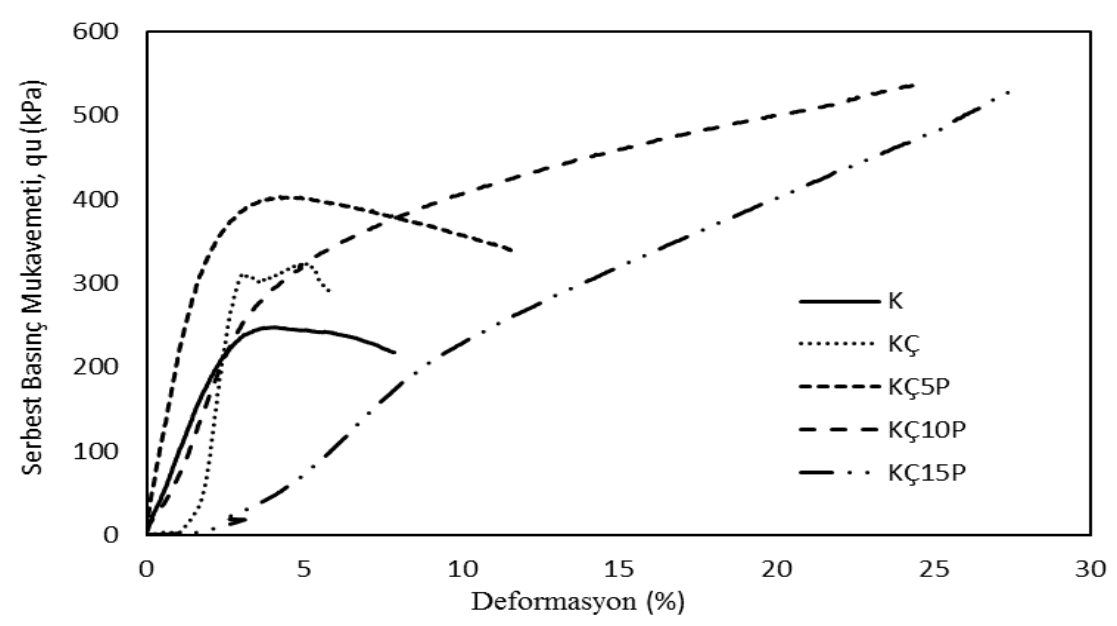

Şekil 9. 0 günlük numunelerin serbest basınç deney sonuçları

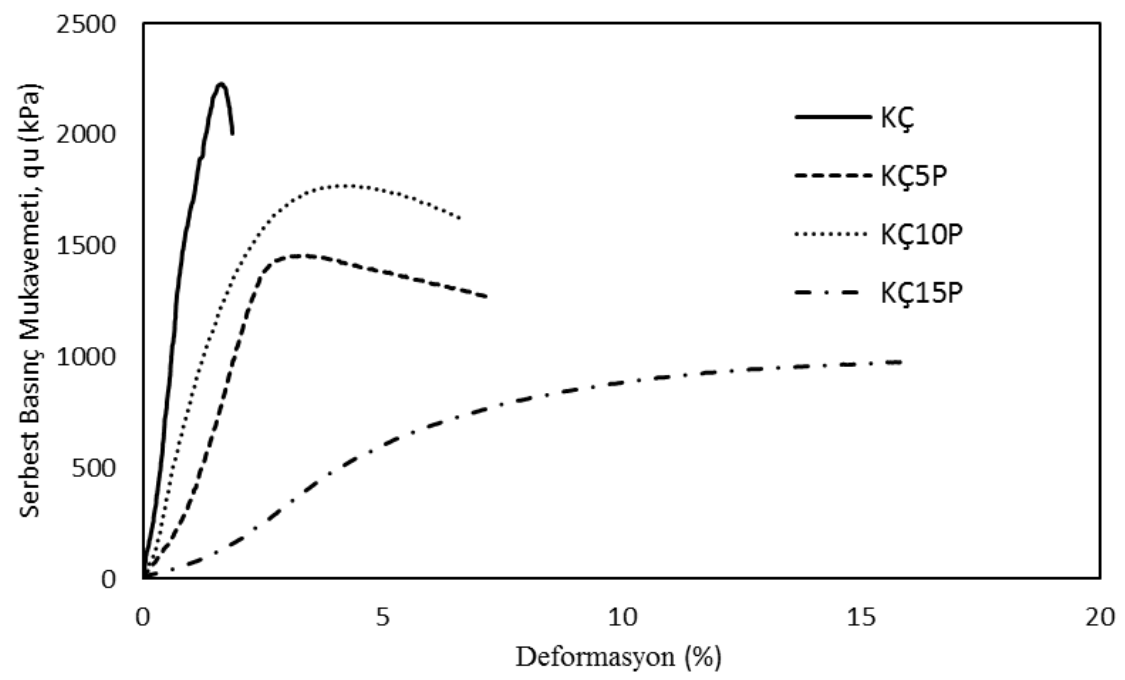

Şekil 10. 28 günlük numunelerin serbest basınç deney sonuçları 
Serbest basınç deneyi yapılan 28 günlük numunelerin deney sonuçlarına serbest basınç mukavemeti açısından bakıldığında (Şekil 10); çimentolu killi numunenin serbest basınç dayanımın atık PVC fiber katkılı numunelere göre daha yüksek olduğu görülmektedir. $\mathrm{Bu}$ durum, çimentolu killi numunenin çimento oranının atık PVC katkılı numunelere göre daha fazla olmasından kaynaklanmaktadır. \%10 atık PVC fiber katkılı zeminin, \%5 ve \%15 atık PVC fiber katkılı zemine göre daha iyi sonuç verdiği görülmektedir. Ayrıca deney sonuçlarına deformasyon açısından bakıldığında, atık PVC fiber oranı arttıkça deformasyon yüzdesinin arttığı görülmektedir.

0 ve 28 günlük deney sonuçları karşılaştırıldığında ise; 28 günlük numunelerin serbest basınç dayanımın 0 günlük numunelere göre daha yüksek olduğu görülmektedir. $\mathrm{Bu}$ sonuç, numune karışımlarında mevcut olan çimentonun zamanla dayanım kazanmasından kaynaklanmaktadır. Deney sonuçları deformasyon açısından karşılaştırıldığında, 0 günlük numunelerin daha yüksek deformasyona kadar dayanım gösterdiği görülmektedir. $\mathrm{Bu}$ durum, çimentonun zamanla numunelerin sünekliğini azalttığını göstermektedir.Literatür araştırması kapsamında, belli oranlarda zemin iyileştirme malzemelerinin zeminlerin mühendislik özelliklerinin iyileştirilmesinde kullanılabileceği görülmüştür. $\mathrm{Bu}$ çalışma kapamında da belli oranlarda atık PVC'nin killi zeminlerin mühendislik özelliklerinin iyileştirilmesinde kullanılabileceği ortaya konmuştur.

\section{Sonuç}

Günümüzde zemin iyileştirme konusu, geoteknik mühendisliğinin vazgeçilmez konularından birisidir. Ayrıca, sanayileşme ve endüstrileşmeye bağlı olarak her gün tonlarca atık malzeme elde edilmektedir. Hem ham madde tüketimini azaltması hem de çevreye olan zararlı etkilerinin azaltılması bakımından, atık malzemelerin tekrar kullanılması önem arz etmektedir.

$\mathrm{Bu}$ çalışma kapsamında yapılan standart kompaksiyon deney sonuçlarına göre, çimentolu kile atık PVC fiberi eklendikçe maksimum kuru birim hacim ağırlık değerinde azalma, optimum su muhtevasında çimento eklenmesiyle azalırken, kil+çimento karışımına atık PVC fiberi eklenmesiyle arttığı gözlenmiştir. Serbest basınç deney sonuçlarına göre, kil numuneye göre atık PVC fiber katkılı numunelerin 0 ve 28 günlük serbest basınç dayanımının daha yüksek olduğu görülmüştür. Sonuç olarak, belli oranlarda atık PVC fiberin killi zeminlerin serbest basınç dayanımını arttırdığı görülmüştür. Atık PVC fiberlerinin zemin iyileştirilmesinde kullanılması ile, hem çevre kirliliğinin azaltılmasına katkı sağlanmış olunmakta, hem de ham madde tüketiminin azaltılması sağlanmaktadır. Gelecekte, farklı oran ve boyutlardaki atık PVC fiberlerin, farklı zeminlerde etkisinin gözlenmesi için çalışmalar planlanmaktadır.

\section{Kaynaklar}

[1]. Okagbue C.O., Yakubu J.A., "Limestone ash waste as a substitute for lime in soil improvement for engineering construction", Bulletin of engineering Geology and the Environment, 2000, 58(2):107-113.

[2]. Martin II J.R., Olgun C.G., Mitchell J.K., Durgunoglu H.T., Emrem C., " Preliminary findings from an investigation of improved ground performance during the 1999 Turkey Earthquakes", In NSF-TUBITAK Turkey-Taiwan Earthquakes Grantee Workshop, 2002, (pp. 24-26).

[3]. Prabakar J., Dendorkar N., Morchhale R.K., "Influence of fly ash on strength behavior of typical soils", Construction and Building Materials, 2004, 18(4):263-267.

[4]. Taşpolat L.T., Zorluer İ., Koyuncu H., "Atık Mermer Tozunun Geçirimsiz Kil Tabakalarda Donma-Çözülmeye Etkisi”, Yapı Teknolojileri Elektronik Dergisi, 2006, 2(2):11-16.

[5]. Aruntaş H., 'Uçucu Küllerin İnşaat Sektöründe Kullanım Potansiyeli', Gazi Üniversitesi Mühendislik-Mimarlık Fakültesi Dergisi, 2006, 21(1):193-203 
[6]. Yıldırım D., Yıldız A., "Geogrid Donatılı Stabilize Dolgu Tabakası İle Kil Zeminlerin İyileştirilmesi'”, Ç.Ü. Fen Bilimleri Enstitüsü Dergisi, 2010, Cilt:22-2

[7]. Paul A., Anumol V.S., Moideen F., Jiksymol K.J., Abraham A., "'Studies on improvement of clayey soil using egg shell powder and quarry dust', International Journal of Engineering Research and Applications, 2014, 4(4):55-63.

[8]. Öntürk K., Fırat S., Vural İ., Khatib J.M., “Uçucu Kül ve Mermer Tozu Kullanarak Yol Altyapısının İyileştirilmesi’, Politeknik Dergisi, 2014, 17(1):35-42.

[9]. Yarbaşı N., "Mermer Tozu ve Atık Lastik ile İyileştirilen Düşük Plastisiteli Killi Zeminlerin Dayanım Özellikleri”, Doğal Afetler ve Çevre Dergisi, 2018, 4(2):162-170.

[10]. Xiao M., Bowen J., Graham M., Larralde J., "Comparison of seismic responses of geosynthetically reinforced walls with tire-derived aggregates and granular backfills", Journal of Materials in Civil Engineering, 2012, 24(11):1368-1377.

[11]. Naeini S.A., Mirzakhanlari M., "The effect of geotextile and grading on the bearing ratio of granular soils"', EJGE, 2008, 13:1-10

[12]. Umu S.U., Okur D.V., Yılmaz G., Fırat S., "Dinamik Yükleme Şartlarında Kum/Lastik Karışımlarının Rijitlik Ve Sönüm Özelliklerinin İncelenmesi’, Politeknik Dergisi, 2014, 17(1):13-21.

[13]. Keskin M.S., Laman M., “Atık Lastik-Kum Karışımlarının Kayma Mukavemetinin Laboratuar Deneyleriyle İncelenmesi”, Çukurova Üniversitesi Mühendislik-Mimarlı Fakültesi Dergisi, 2012, 27(2):27-36.

[14]. Freitag D.R., "Soil randomly reinforced with fibers", Journal of Geotechnical Engineering, 1986, 112(8):823-826.

[15]. Kumar A., Walia B.S., Bajaj A., "Influence of fly ash, lime, and polyester fibers on compaction and strength properties of expansive soil", Journal of materials in civil engineering, 2007, 19(3):242-248.

[16]. Yetimoglu T., Salbas O., " A study on shear strength of sands reinforced with randomly distributed discrete fibers", Geotextiles and Geomembranes, 2003, 21(2):103-110.

[17]. Lee K.M., Manjunath V.R., "Soil-geotextile interface friction by direct shear tests", Canadian geotechnical journal, 2000, 37(1):238-252.

[18]. Zhang M.X., Javadi A.A., Min X., "Triaxial tests of sand reinforced with 3D inclusions", Geotextiles and Geomembranes, 2006, 24(4):201-209.

[19]. Naeini S.A., Naderinia B., Izadi E., "Unconfined compressive strength of clayey soils stabilized with waterborne polymer', KSCE Journal of Civil Engineering, 2012, 16(6):943949.

[20]. Ateş A., "The effect of polymer-cement stabilization on the unconfined compressive strength of liquefiable soils', International Journal of Polymer Science, 2013.

[21]. Naeini S.A., Sadjadi S.M., "Effect of waste polymer materials on shear strength of unsaturated clays', EJGE Journal, 2008, 13:1-12.

[22]. Özdilek, C., "Katkılı Pet ve Pvc Atıklarının Seçimli Olarak Ayrılmasına Yönelik Yüzey Özelliklerinin Araştırılması", Yüksek Lisans Tezi, İstanbul Teknik Üniversitesi, Fen Bilimleri Enstitüsü, 2011

[23]. TS 1900-1, “İnşaat Mühendisliğinde Zemin Lâboratuvar Deneyleri-Bölüm 1: Fiziksel Özelliklerin Tayini', (2006).

[24]. TS 1500, “İnşaat Mühendisliğinde Zeminlerin Sınıflandırılması’, (2000).

[25]. TS 1900-2, “İnşaat Mühendisliğinde Zemin Lâboratuvar Deneyleri-Bölüm 2: Mekanik Özelliklerin Tayini”, (2006). 